\title{
Evidence-based approach for managing hypertension in type 2 diabetes
}

\author{
This article was published in the following Dove Press journal: \\ Integrated Blood Pressure Control \\ 24 May 2010 \\ Number of times this article has been viewed
}

\author{
Gerti Tashko' \\ Robert A Gabbay² \\ 'Division of Endocrinology, Diabetes, \\ and Metabolism, Penn State College of \\ Medicine, Hershey, PA, USA; ${ }^{2}$ Penn State \\ Institute for Diabetes and Obesity, \\ Penn State College of Medicine, Penn \\ State Milton S Hershey Medical Center, \\ Hershey, PA, USA
}

\begin{abstract}
Blood pressure (BP) control is a critical part of managing patients with type 2 diabetes. Perhaps it is the single most important aspect of diabetes care, which unlike hyperglycemia and dyslipidemia can reduce both micro- and macrovascular complications. Hypertension is more prevalent in individuals with diabetes than general population, and in most cases its treatment requires two or more pharmacological agents (about 30\% of individuals with diabetes need 3 or more medications to control BP). In this article we describe the key evidence that has contributed to our understanding that reduced BP translates into positive micro- and macrovascular outcomes. We review the data supporting current recommendation for BP target $<130 / 80 \mathrm{mmHg}$. Two studies suggest that a lower BP goal could be even more beneficial. We also present the comparative benefits of various antihypertensive drugs in reducing diabetes-related micro- and macrovascular complications. Finally we propose an evidence-based algorithm of how to initiate and titrate antihypertensive pharmacotherapy in affected individuals. Overall, achieving $\mathrm{BP}<130 / 80 \mathrm{mmHg}$ is more important than searching for the "best" antihypertensive agent in patients with diabetes.
\end{abstract}

Keywords: blood pressure control, treatment protocol, fixed dose combination, clinical inertia, adherence

\section{Introduction}

Diabetes is very prevalent and places high financial burden to our society. In the United States during 2009 to 2034 the number of persons with diabetes is anticipated to increase from 23.7 million to 44.1 million. The relative annual cost is also expected to rise from $\$ 113$ billion to $\$ 336$ billion during the same period. ${ }^{1}$ Worldwide, 366 million individuals are projected to have diabetes by year $2030 .^{2}$ Type 2 diabetes, the predominant form, comprises $90 \%$ to $95 \%$ of all cases.

Macrovascular disorders are common in affected individuals. Specifically, cardiovascular disease (CVD) is 2 to 5 times more prevalent in persons with diabetes than general population. ${ }^{3-5}$ Importantly it is the most serious complication by contributing $70 \%$ to all-cause mortality in affected patients. ${ }^{6}$ In the United States, diabetes is also the leading cause of microvascular disorders of end stage renal disease (ESRD) ${ }^{7,8}$ and retinopathy. ${ }^{9}$

Hypertension is 1.5 to 2.0 times more common in patients with diabetes than without diabetes, ${ }^{10}$ and more so in females than males. ${ }^{11}$ For example, about $40 \%$ of individuals between ages 25 to 65 already have high blood pressure (BP) at the time of diagnosis of diabetes. ${ }^{11}$ This figure increases further with age. ${ }^{4,11}$ Coexistence of hypertension with diabetes is likely due to the confounding effect of metabolic syndrome that often predates both conditions.
Correspondence: Robert A Gabbay, MD, PhD Diabetes Program, Penn State Milton S Hershey Medical Center, 500 University Drive, H044, Room C6630, Hershey, PA 17033, USA

$\mathrm{Tel}+\mathrm{I}(7 \mathrm{I}) 53 \mathrm{I}-3592$

$\mathrm{Fax}+\mathrm{I}(717) 531-5726$

Email rgabbay@psu.edu 
Hypertension is not only common but also a major cause of cardiovascular (CV) pathology ${ }^{11-14}$ and thus mortality in individuals with diabetes. It is also a direct contributor to microvascular complications of nephropathy ${ }^{7,15,16}$ and retinopathy. ${ }^{16-18}$ As described in the main text, many randomized clinical trials have documented that good BP control reduces both micro- and macrovascular complications. This could make hypertension the single most important determinant of diabetes-related morbidity and mortality compared to hyperglycemia that mainly causes microvascular disease and dyslipidemia that mostly contributes to macrovascular complications.

For this review article, we searched the literature for clinical studies related to treatment of hypertension in type 2 diabetes. We utilized PubMed to find trials published in 2005 to 2010 . We then used citations from identified articles to select landmark studies printed before 2005. For this paper we chose mainly randomized clinical trials with large sample size and long duration of follow up. We narrowed further our selection to original works that emphasized renal and CV outcomes of various antihypertensive therapies in subjects with type 2 diabetes.

The purpose of this article is 5-fold. First, to provide evidence that reducing BP is beneficial in patients with diabetes; second, to demonstrate that optimal BP target is $<130 / 80 \mathrm{mmHg}$; third, to show that hypertension is poorly controlled in clinical practice worldwide; fourth, to explain the rationale of choosing the right antihypertensive medications; and fifth, to provide a descriptive algorithm of how to initiate and titrate pharmacotherapy.

\section{Reducing BP is beneficial}

Critical evidence from 2 major trials, UKPDS ${ }^{18,19}$ and SHEP, ${ }^{20}$ shows that reduced BP prevents complications in patients with type 2 diabetes.

UKPDS $38^{18}$ was a landmark study that examined if decreased BP in persons with new type 2 diabetes lowered micro- and macrovascular complications. At study entry, 1148 subjects with less than 3 years of diabetes and mean BP 164/94 mmHg were randomized into "tight" BP and "less-tight" BP control groups. Patients in the tight BP control group received either angiotensin converting enzyme inhibitor (ACEi) captopril or $\beta$-blocker atenolol to bring BP to $<150 / 85 \mathrm{mmHg}$. The less-tight BP control group could use medications other than ACEi or $\beta$-blocker to attain $\mathrm{BP}<180 / 105 \mathrm{mmHg}$.

After 8.4 years of follow up, the tight BP control group achieved a lower BP than the less-tight BP control arm
$(\Delta 10 / \Delta 5 \mathrm{mmHg})$, resulting in greater relative reductions $(P<0.05)$ for both micro and macrovascular complications: $24 \%$ in any diabetes related end-points, $32 \%$ in diabetesrelated deaths, $44 \%$ in strokes, $56 \%$ in heart failure (HF) and $34 \%$ in retinopathy. No difference in outcomes was seen in patients treated with either captopril or atenolol. Of note, about $30 \%$ of patients in the tight BP control group required 3 or more antihypertensive medications to achieve the desired BP.

UKPDS $39^{19}$ was a 10 -year observational study on the same group of patients who participated in the original UKPDS $38^{18}$ trial. It examined if reduced vascular complications obtained in the UKPDS 38 were maintained 10 years after the end of randomization. Subjects $(\mathrm{N}=884)$ underwent post-trial monitoring by clinic visits for the first 5 years and then by questionnaires for the next 5 years. The following 2 results were observed. The BP difference between groups, obtained during the original study, was lost within 2 years of the observational phase. More importantly, the significant relative reductions achieved in the tight BP control arm during UKPDS $38^{18}$ were not sustained 10 years later. It is prudent to conclude that UKPDS $39^{19}$ shows the significance of not only decreasing BP in patients with diabetes but also maintaining it indefinitely in order to keep a low incidence of micro- and macrovascular complications.

SHEP $^{20}$ examined if a low dose thiazide diuretic prevented major $\mathrm{CV}$ events in older patients with isolated systolic hypertension. At study entry, $12 \%$ of 4736 subjects had diabetes with mean systolic BP $>160 \mathrm{mmHg}$ and diastolic $\mathrm{BP}<90 \mathrm{mmHg}$. Participants were randomized into 2 groups: chlorthalidone 12.5 to $25 \mathrm{mg}$ /day or placebo. Primary outcome was the occurrence of fatal and nonfatal strokes, fatal and nonfatal myocardial infarction (MI), major CV events, or all-cause mortality.

After 5 years of follow up, the chlorthalidone group achieved a lower BP than the placebo $\operatorname{arm}(\Delta 9.8 / \Delta 2.2 \mathrm{mmHg})$, resulting in greater relative reductions $(P<0.05): 34 \%$ in major CV events, $54 \%$ in fatal and nonfatal MIs and $56 \%$ in major coronary heart disease (CHD) events. Patients with diabetes experienced an absolute benefit twice greater than nondiabetic individuals. This most likely reflected the fact that baseline CV risk was higher in persons with diabetes.

In summary, UKPDS $38,{ }^{18}$ UKPDS $39,{ }^{19}$ SHEP $^{20}$ and other studies like HDFP, ${ }^{12}$ Syst-Euro, ${ }^{21}$ HOT, ${ }^{22}$ normotensive $\mathrm{ABCD}^{16}$ and $\mathrm{HOPE}^{23}$ provide firm evidence that even small $\mathrm{BP}$ reductions translate to significant decrease in both micro and macrovascular complications in persons with type 2 diabetes. These findings have major consequences given that 
hypertension contributes directly to CV pathology, which in turn is the most common cause of mortality in diabetic individuals. ${ }^{6}$ Therefore it is imperative that providers screen and treat hypertension aggressively in patients with diabetes.

\section{Evidence for BP less than $130 / 80 \mathrm{mmHg}$}

Clear evidence supports the current recommendation that target BP must be $<130 / 80 \mathrm{mmHg}$ in patients with diabetes. ${ }^{24-28}$ This comes primarily from results of $\mathrm{HOT}^{22}$ and Normotensive $\mathrm{ABCD}^{16}$ clinical trials.

The HOT study examined the lowest diastolic BP that could have the greatest impact in reducing $\mathrm{CV}$ events in patients with hypertension. At study entry, $8 \%$ of 18790 participants with mean BP 170/105 mmHg had diabetes. Subjects were randomized into 3 different treatment intensities so that final diastolic BP in each group was $\leq 80, \leq 85$ or $\leq 90 \mathrm{mmHg}$. Treatment was intensified based on BP response. Primary outcome was the occurrence of fatal or nonfatal MI, fatal or nonfatal strokes, or deaths from any $\mathrm{CV}$ cause.

After 3.8 years of follow up, the 3 groups achieved the following diastolic BPs: $81.1,83.2$ and $85.2 \mathrm{mmHg}$. Importantly, among 1501 patients with diabetes, the composite primary outcomes occurred remarkably $51 \%$ less $(P=0.005)$ in the arm with target diastolic $\mathrm{BP} \leq 80 \mathrm{mmHg}$ than in the one with target $\leq 90 \mathrm{mmHg}$. The $\mathrm{HOT}^{22}$ trial clearly demonstrates the need to achieve a diastolic $\mathrm{BP} \leq 80 \mathrm{mmHg}$ in patients with diabetes.

The normotensive $\mathrm{ABCD}^{16}$ trial examined if further reduction of normal BP could prevent more vascular complications in patients with diabetes. At the time, BP $<140 / 90 \mathrm{mmHg}$ was considered normal. At study entry, 480 participants with type 2 diabetes and mean BP 136/84 mmHg were randomized into ACEi enalapril, calcium channel blocker (CCB) nisoldipine, or placebo arm. The goal was to lower the diastolic BP from baseline by $10 \mathrm{mmHg}$ in the treatment groups and maintain it at 80 to $89 \mathrm{mmHg}$ in the placebo arm.

After 5.3 years of follow up, the enalapril and nisoldipine groups achieved a BP $128 / 75 \mathrm{mmHg}$ and placebo arm a BP 137/81 mmHg. The lower BP treatment groups experienced significantly less strokes $(P=0.03)$, retinopathy $(P=0.019)$ and progression of normoalbuminuria $(P=0.012)$ or microalbuminuria $(P=0.028)$ than the placebo arm. Similar benefits were seen between patients receiving either enalapril or nisoldipine.

In conclusion, results from both $\mathrm{HOT}^{22}$ and normotensive $\mathrm{ABCD}^{16}$ trials have clearly established that
$\mathrm{BP}<130 / 80 \mathrm{mmHg}$ is an appropriate target for treatment of hypertension in patients with diabetes.

\section{Could a lower BP target be more optimal?}

Some evidence implies that even a lower BP goal than 130/80 $\mathrm{mmHg}$ could be beneficial in decreasing micro and macrovascular complications of type 2 diabetes. Data from prospective observational UKPDS $36^{29}$ study and randomized interventional ABCD- $2^{30}$ trial are suggestive of this possibility.

UKPDS 36 examined the relationship between systolic $\mathrm{BP}$ and rate of vascular complications in 3642 individuals with new diabetes and mean systolic BP $135 \mathrm{mmHg}$. Primary outcome was the occurrence of any diabetes-related complications or all-cause mortality. After 10.5 years of follow up, a linear relationship was observed between systolic BP and complications from diabetes. Every $10 \mathrm{mmHg}$ decrease in systolic BP was associated with significant reductions in final outcomes by: $12 \%$ in diabetes related complications, $15 \%$ in diabetes-related deaths, $11 \%$ in MIs and $13 \%$ in microvascular complications. Remarkably, there was no minimal systolic BP threshold at which complication rates stabilized or worsened. The lowest risk was seen in subjects with systolic $\mathrm{BP}<120 \mathrm{mmHg}$.

The randomized $\mathrm{ABCD}-2^{30}$ trial examined if angiotensin receptor blocker (ARB) valsartan could prevent progression of normo or microalbuminuria in patients with type 2 diabetes, who had normal BP and kidney function. At enrollment, 129 subjects with mean BP 126/84 mmHg were randomized to receive either valsartan $80 \mathrm{mg} /$ day or placebo. After 1.9 years of follow up, the valsartan arm achieved a BP 118/75 mmHg and placebo group a BP 124/80 $\mathrm{mmHg}$ $(P<0.001)$. The primary outcome, which was the progression of albuminuria, occurred significantly less in the tight $\mathrm{BP}$ arm than in the placebo group $(P=0.007)$, implying that the relative decrease in albuminuria was a direct consequence of reduced $\mathrm{BP}$.

However, no differences in glomerular filtration rate (GFR) or retinopathy were detected between groups, which could be explained by the short duration of the trial. The study outcome is important given the well known association of microalbuminuria with the risk of renal insufficiency ${ }^{31}$ and CVD. ${ }^{32,33}$ For example, HOPE trial showed clearly that every $0.4 \mathrm{mg} / \mathrm{mmol}$ rise in urine albumin/creatinine ratio contributed to $5.9 \%$ increase in risk of $\mathrm{CV}$ events. ${ }^{32}$

In conclusion, both UKPDS 36 and ABCD-2 studies suggest a possible benefit in reducing $\mathrm{BP}$ further to a 
target $<120 / 75 \mathrm{mmHg}$ in patients with diabetes. However longer randomized clinical trials using various antihypertensive drugs are needed to test this hypothesis rigorously. Such trials must also include high risk subjects with multiple comorbidities.

\section{Blood pressure is uncontrolled in clinical practice}

Although BP control is the most important variable in preventing micro and macrovascular complications, observational studies consistently show that BP target is not achieved in most patients with type 2 diabetes. It is estimated that only $2.7 \%$ to $30 \%$ of individuals reach BP goal $<130 / 80$ mmHg. ${ }^{34-40}$ For example, a large analysis of 49,420 individuals with diabetes and hypertension, from 24 original studies conducted in different countries between 1990 and 2004, found that although $87 \%$ of patients were receiving antihypertensive therapy, only $12 \%$ had achieved BP target $<130 / 85$ mmHg. ${ }^{38}$

The 2005 to 2006 National Health and Nutrition Examination Survey (NHANES) documented 29.3\% control rate of BP among 481 individuals with diabetes. ${ }^{36}$ A recent observational study from the Swedish National Diabetes Register conducted in 4570 patients with type 2 diabetes and CHD found that although $94 \%$ of subjects were taking antihypertensive medications, only $23 \%$ had achieved BP $<130 / 80 \mathrm{mmHg}$. Surprisingly, it was observed that among the three major risk factors for diabetes-related complications, BP target was attained in fewer subjects than were glycemic and cholesterol goals: hemoglobin $\mathrm{A}_{1 \mathrm{c}}<7 \%$ and low density lipoprotein $<100 \mathrm{mg} / \mathrm{dL}$ were reached in $52 \%$ and $63 \%$ of individuals respectively. ${ }^{35}$ The $2005-2006$ NHANES and observational study by McFarlane et al also found that BP was the least frequently controlled variable of all three major risk factors. ${ }^{36,37}$

Two important factors contribute to poor BP control in patients with diabetes: adherence to therapy and clinical inertia. Adherence is most commonly measured by the medication possession ratio (MPR), which was defined originally in 2000 by Bertholet. ${ }^{41}$ Adherence to antihypertensive treatment was evaluated recently by a systematic review of 53 original studies published in 2000 to 2005 . Results showed that 12 -month MPR was only $67 \%$, indicating that patients were not on therapy $33 \%$ of the time over a 1 -year period. ${ }^{42}$ Although the review was performed in hypertensive individuals, adherence is expected to be even lower in patients with diabetes, given their tighter BP goal and need for more medication use. ${ }^{18,36,43}$
Adherence to treatment is challenging in all clinical populations. Although many barriers to therapy exist, style of clinician counseling can be fundamental in ensuring adherence. Behavior change techniques like motivational intervention are promising in engaging patients to face ambivalence to treatment, identify barriers to therapy, and discus treatment decisions. ${ }^{44,45}$ Future research is required to adapt these techniques into routine clinical practice for optimal results. ${ }^{44,46}$

Clinical inertia quantifies the failure of providers to escalate treatment in the face of the obvious need to do so. ${ }^{47}$ The prospective study ABATe evaluated clinical inertia for treatment of hypertension in 1169 patients with diabetes from 9 Veteran Administration facilities during 2005 to $2006 .{ }^{48}$ Although average systolic BP was $>140 / 90 \mathrm{mmHg}$ on 2 consecutive years - at the time of clinic visit, $51 \%$ of individuals did not receive intensified therapy. Treatment change was even less likely to occur if BP was between $130 / 80$ and $140 / 90 \mathrm{mmHg}$. In a large cross-sectional study of 35,424 subjects with elevated BP, conducted in 2003 to 2004, clinical inertia for management of hypertension was $37 \%$. Coexistence of diabetes in these individuals was associated with significantly higher rates of clinical inertia. ${ }^{49}$

Physicians' conflicting demands of care, time constraints and perceived patient resistance can contribute to clinical inertia. Methods like registries with graphical depiction of BP trends can help providers identify patients with chronic high BP measurements. ${ }^{50}$ This could ultimately help reduce clinical inertia. Increasing evidence also supports the role of other team members in using protocol-driven antihypertensive therapy to achieve optimal outcomes. ${ }^{44,46,51}$

\section{Therapeutic options}

\section{Angiotensin converting enzyme inhibitors (ACEi)}

In this section we show key evidence from trials BENE$\mathrm{DICT}^{52}, \mathrm{CAPPP}^{53,54}$ and $\mathrm{HOPE}^{23}$ that ACEi are superior to other drug classes in preventing nephropathy and CVD in patients with diabetes. These benefits are independent of the BP-lowering effect, thus making ACEi ideal firstline antihypertensive agents in individuals with type 2 diabetes.

\section{Renal outcomes}

It is well documented that ACEi are renoprotective in persons with diabetes, who have either hypertension, microalbuminuria or renal insufficiency. ${ }^{52,55-59}$ An important example is the BENEDICT $^{52}$ study, in which 1204 individuals with diabetes, 
mean BP 150/87 and normoalbuminuria received either placebo, ACEi, CCB or ACEi + CCB combination therapy. After 3 years of follow up, BP values were similar among all groups (about 140/80 mmHg), yet microalbuminuria occurred significantly less in subjects treated with ACEibased therapy than in those receiving $\mathrm{CCB}$ or placebo.

In conclusion, BENEDICT ${ }^{52}$ and other randomized clinical trials, like those by Ahmad et $\mathrm{al}^{55}$ and Lewis et $\mathrm{al}^{56}$ show clearly that ACEi reduce microalbuminuria and rate of nephropathy in patients with type 2 diabetes apart from their antihypertensive effect.

\section{Cardiovascular outcomes}

More importantly, several trials document that ACEi decrease diabetes-related $\mathrm{CV}$ complications apart from their antihypertensive effect. The first study to address this issue was CAPPP. ${ }^{53,54}$ It examined if the ACEi captopril lowers macrovascular outcomes more than a diuretic or $\beta$-blocker in patients with diastolic BP $\geq 100 \mathrm{mmHg}$. At study entry, $4.9 \%$ of 10,985 subjects had diabetes. After 6.1 years of follow up, study groups achieved similar BP 154/89 mmHg but with different end-points. Patients with diabetes receiving captopril experienced greater significant reductions than those treated with a diuretic or $\beta$-blocker: $41 \%$ in combined primary outcomes (fatal and nonfatal MI, fatal and nonfatal strokes, or CV deaths), $66 \%$ in nonfatal MIs and $46 \%$ in total mortality.

It is worth pointing that although CAPPP trial showed superiority of ACEi over $\beta$-blockers, the same benefit was not seen in the UKPDS $38^{18}$ study. This discrepancy could be explained by the fact that subjects enrolled in the UKPDS were recently diagnosed with diabetes and therefore of low baseline $\mathrm{CV}$ risk.

Evidence from the $\mathrm{HOPE}^{23}$ trial further supports the CV benefits of ACEi independently of their BP-lowering effect. At study entry, 3577 subjects with diabetes had mean BP 142/80 $\mathrm{mmHg}$, coronary artery disease (CAD), peripheral arterial disease (PAD) or stroke. Participants were randomized to receive either ramipril $10 \mathrm{mg} /$ day or placebo. Primary outcome was the occurrence of MI, stroke or CVD, with overt nephropathy being a substudy end-point. Subjects were followed for 4.5 years; however, the trial was terminated 6 months earlier due to consistent benefits of ACEi over placebo. The ramipril group achieved a slightly lower BP than the placebo arm $(\Delta 2.4 / \Delta 1.0 \mathrm{mmHg})$.

However when BP differences were adjusted, patients with diabetes receiving ramipril experienced greater significant reductions than those treated with placebo: $24 \%$ in overt nephropathy, $22 \%$ in MI, $33 \%$ in strokes, $37 \%$ in CV deaths and $25 \%$ in combined CV events. After the trial ended and the randomization was lost, participants were monitored for an additional 2.6 years. ${ }^{60}$ The use of ACEi was similar in both groups, but patients who were previously in the ramipril arm experienced additional 19\%, 16\% and 34\% relative reductions in MIs, revascularizations and incidence of new diabetes respectively.

$\mathrm{CAPPP}^{53,54}$ and $\mathrm{HOPE}^{23}$ trials have shown clearly the CV benefits of ACEi compared to placebo, diuretics or $\beta$-blockers. Positive CV outcomes of ACEi over diuretics were also seen in the ANBP ${ }^{61}$ study during 4.1 years of observation. Similarly, 3 major randomized trials; hypertensive ABCD, ${ }^{62}$ STOP- $2^{63}$ and FACET, ${ }^{64}$ reveal the superiority of ACEi over dihydropyridine $\mathrm{CCB}$ in reducing macrovascular events and especially MI, in hypertensive subjects with diabetes. These results were seen over a period of 3.5 to 5 years and were independent of the BP-lowering effect of ACEi. ${ }^{62-64}$ Collectively the above 6 studies support the use of ACEi as first-line therapy for hypertension in patients with type 2 diabetes.

\section{Angiotensin receptor blockers (ARB)}

Data suggests that ARB could also be first-line treatment of hypertension in individuals with diabetes. Over the last decade, several randomized clinical studies have shown that interruption of the renin-angiotensin system by ARB is equally beneficial in lowering BP and rate of diabetic nephropathy. However their relative importance in preventing $\mathrm{CV}$ outcomes is rather inconsistent.

\section{Renal outcomes}

Three key randomized trials, RENAAL, ${ }^{65}$ IDNT $^{66}$ and Parving et $\mathrm{al}^{67}$ have established that ARB are renoprotective in diabetes, apart from their antihypertensive effect.

The RENAAL study compared ARB losartan with placebo in 1513 patients with diabetes, mean BP 153/82 mmHg and baseline serum creatinine 1.9. After 3.4 years of follow up, both groups achieved similar BP values, but subjects receiving losartan experienced $25 \%$ more reduction in serum creatinine doubling $(P<0.05)$ and $28 \%$ greater decrease in development of ESRD $(P<0.05)$ than those treated with placebo.

IDNT $^{66}$ trial had a similar design. Subjects $(\mathrm{N}=1715)$ with diabetes, mean BP 159/87 mmHg and baseline serum creatinine 1.66 were randomized into the ARB irbesartan, CCB amlodipine, or placebo groups. After 2.6 years of follow up, the irbesartan arm experienced $23 \%$ and $20 \%$ more significant reductions in composite end-points of serum creatinine doubling, ESRD, or death from any cause than the 
amlodipine and placebo group, respectively. Results were independent of the BP-lowering effects.

A third trial, by Parving et a $l^{67}$ compared irbesartan at 2 doses $(150 \mathrm{mg} /$ day and $300 \mathrm{mg} /$ day $)$ with placebo in preventing nephropathy in 590 patients with diabetes, who had mean BP 153/90 mmHg and normal renal function, but baseline microalbuminuria. After 2 years of follow up, when adjusted for differences in initial urinary albumin excretion (UAE) and final BP values, nephropathy - defined by UAE $>200 \mu \mathrm{g} / \mathrm{min}$ or $30 \%$ rise from baseline - occurred significantly less in the irbesartan $150 \mathrm{mg} /$ day and irbesartan $300 \mathrm{mg} /$ day groups than in the placebo arm by $39 \%$ and $70 \%$, respectively.

However, it is important to add that ARB might be harmful in a subset of patients at high risk for vascular complications. In the recent randomized TRANSCEND ${ }^{68}$ trial $(\mathrm{N}=5926)$, after 4.6 years of observation, telmisartan $80 \mathrm{mg} /$ day increased creatinine doubling 59\% more than placebo, although no difference in the occurrence of dialysis was detected between groups. Diabetes was present in 36\% of participants.

In conclusion, ARB are overall more effective than $\mathrm{CCB}$ and placebo in decreasing microalbuminuria and rate of nephropathy in persons with diabetes, independently of their BP-lowering effect.

\section{Cardiovascular outcomes}

There is conflicting evidence whether ARB prevent CVD apart from their antihypertensive effect in patients with diabetes.

For example, LIFE $^{69}$ demonstrated that ARB losartan reduced $\mathrm{CV}$ events greater than $\beta$-blocker atenolol in individuals with diabetes. At study entry, $13 \%$ of 9193 subjects with diabetes, mean BP 174/98 and left ventricular hypertrophy (LVH) were randomized to receive either losartan or atenolol. After 4 years of follow up, although BP decreased similarly in both groups $(\Delta 30 / \Delta 17 \mathrm{mmHg})$, combined $\mathrm{CV}$ events (death, MI or stroke) and strokes occurred significantly less in the ARB group than in the $\beta$-blocker arm by $13 \%$ and $25 \%$, respectively.

Of interest, the following significant differences were observed in the losartan group compared to atenolol arm: less adverse effects, fewer cases of new-onset diabetes and greater decrease in LVH. In conclusion, like ACEi captopril in the CAPPP ${ }^{53,54}$ trial, ARB losartan performed better than $\beta$-blocker in preventing $\mathrm{CV}$ events in patients with diabetes. This was independent of BP-lowering effect and likely due to direct reduction of the left ventricular mass.
However, there are some contrary results from trials, SCOPE,${ }^{70}$ VALUE $^{71}$ and TRANSCEND. ${ }^{72}$ ARB blocker was not superior to placebo in SCOPE $(\mathrm{N}=4964)$, or to CCB in VALUE study $(\mathrm{N}=15245)$ in reducing composite $\mathrm{CV}$ outcomes over a period of about 4 years. In both studies diabetes was present in $12 \%$ and $34 \%$ of participants, respectively. However, in SCOPE, the ARB did reduce the secondary outcome of nonfatal strokes $28 \%$ more than placebo $(P<0.05)$.

Recently, TRANSCEND ${ }^{72}$ examined the efficacy of telmisartan versus placebo in preventing $\mathrm{CV}$ events in high risk patients, who were intolerable to ACEi. At enrollment, of 5926 individuals with CAD, PAD or stroke, $36 \%$ had diabetes. After 4.6 years of observation, ARB therapy lowered BP significantly more than placebo $(\Delta 3.2 / \Delta 1.3 \mathrm{mmHg})$. Unexpectedly, however, telmisartan $80 \mathrm{mg} /$ day did not reduce the composite primary outcomes of $\mathrm{CV}$ death, MI, stroke, or HF hospitalizations more than placebo.

In conclusion, the overall evidence supports the usefulness of ARB in decreasing the rate of nephropathy apart from their BP-lowering effect. However, given the inconsistent benefits in preventing $\mathrm{CV}$ outcomes compared to $\mathrm{CCB}$ and placebo, ARB could be less favorable than ACEi as firstline agent for treatment of hypertension in type 2 diabetes (indirect evidence).

\section{ACEi versus $A R B$}

In this section we show the direct evidence documenting equivalence between ACEi and ARB in preventing renal and CV outcomes; therefore, suggesting the use of ARB as a first-line agent. We also demonstrate that their combination is not more beneficial than each drug alone in patients with type 2 diabetes.

\section{Renal outcomes}

Two important randomized trials, DETAIL ${ }^{73}$ and by Lacourciere et $\mathrm{al}^{74}$ show that ACEi and ARB therapies are equally renoprotective in diabetes. DETAIL examined if telmisartan was equivalent to enalapril in retarding worsening of renal insufficiency in subjects with type 2 diabetes, mean BP 152/85 mmHg and early nephropathy. At study entry, 250 participants with GFR of $>90 \mathrm{~mL} / \mathrm{min}$ were randomized into enalapril $20 \mathrm{mg} /$ day or telmisartan $80 \mathrm{mg}$ /day groups. After 5 years of follow up, no significant differences in BP reduction or GFR decline (primary outcome) were detected between the two groups.

Analogous results were seen between ACEi enalapril and ARB losartan in persons with diabetes in a smaller 
randomized trial $(\mathrm{N}=92)$ by Lacourciere et al. At 1 year, enalapril and losartan treatments were equivalent in lowering $\mathrm{BP}$, and delaying both the progression of albuminuria and GFR fall. ${ }^{74}$ In summary the smaller studies, DETAIL ${ }^{73}$ and by Lacourciere et $\mathrm{al}^{74}$ suggest that ACEi and ARB are equally renoprotective in patients with type 2 diabetes.

\section{Cardiovascular outcomes}

Equivalence between ARB and ACEi therapy in preventing $\mathrm{CV}$ events in persons with diabetes comes from two important randomized trials, ONTARGET ${ }^{75}$ and VALIANT. ${ }^{76}$

ONTARGET compared ARB and ARB + ACEi combination treatment against ACEi therapy alone. Subjects $(\mathrm{N}=25,620)$ with mean BP $142 / 82 \mathrm{mmHg}$ and established $\mathrm{CAD}, \mathrm{PAD}$, or stroke were randomized to receive either telmisartan, enalapril, or both. At study entry, $37 \%$ of participants had diabetes. Primary outcome was the occurrence of MI, stroke, CV death, or hospitalization from HF. After 4.6 years of follow up, the telmisartan and telmisartan + enalapril groups achieved a slightly lower BP than the enalapril arm $(\Delta 0.9 / \Delta 0.6$ and $\Delta 2.4 / \Delta 1.4 \mathrm{mmHg}$ respectively). However, the small difference in BP did not translate into improved composite primary outcomes in those receiving either telmisartan or telmisartan + enalapril therapy.

Two important observations were seen in subjects treated with both ACEi and ARB compared to ACEi alone. First, the ACEi + ARB combination group experienced a 9\% significant relative rise in composite end-points of dialysis, creatinine doubling or death. ${ }^{77}$ Second, the combined therapy caused significantly more adverse events in the form of hypotension, syncope and renal insufficiency than ACEi. On the other hand, the telmisartan and enalapril groups achieved similar outcomes with similar overall side effects.

Analogous results were seen in the VALIANT ${ }^{76}$ trial, which compared ACEi captopril versus ARB valsartan versus both in preventing macrovascular complications in normotensive subjects with acute MI. Of 14,808 individuals, 23\% had diabetes. After 2.6 years of follow up, although the ACEi + ARB group achieved a slightly lower BP than the ACEi arm $(\Delta 2 / \Delta 1 \mathrm{mmHg}, P<0.05)$, the primary outcome - all cause mortality, CV mortality, recurrent MI, or hospitalization from $\mathrm{HF}$ - occurred similarly among all three interventional groups. In addition, patients treated with $\mathrm{ACE} i+\mathrm{ARB}$ experienced more hypotensive episodes than those receiving ACEi alone $(P<0.05)$, thus resulting in frequent lowering or withdrawal of the combined therapy with ACEi + ARB.

In conclusion, ONTARGET ${ }^{75}$ and VALIANT ${ }^{76}$ show that $\mathrm{ARB}$ and $\mathrm{ACE} i$ treatments are equivalent in preventing $\mathrm{CV}$ outcomes in high risk patients with diabetes. This suggests that ARB could be first-line antihypertensive therapy as well in diabetes. However, the combination of ARB with ACEi was nonsuperior in end-points and caused more adverse events than the ACEi alone. This makes the ARB + ACEi combined regimen undesirable for treatment of hypertension in persons with type 2 diabetes.

\section{$\mathrm{CCB}$, diuretics and $\beta$-blockers}

Given that most patients with diabetes will require 2 or more drugs to treat hypertension, ${ }^{18,36,43}$ it is important to find the most suitable second-line therapeutic agent. This applies also to patients who are intolerant of ACEi or ARB. Such information could be extrapolated from results of 4 major trials: ALLHAT, ${ }^{78}$ INSIGHT, ${ }^{79}$ NORDIL $^{80}$ and INVEST.${ }^{81}$

ALLHAT examined 33,357 subjects with mean BP 146/84 $\mathrm{mmHg}$ and established CHD, of which $36 \%$ had diabetes. Participants were randomized into 4 treatment groups: diuretic chlorthalidone, CCB amlodipine, ACEi lisinopril or $\alpha$-blocker doxazosin. Primary outcome was the occurrence of combined fatal CHD and nonfatal MI. The doxazosin arm was terminated early due to increased incidence of HF. After 4.9 years of observation, the primary outcome was similar among all three antihypertensive drugs.

However, for secondary end-points, the following differences were seen: the incidence of new HF in the amlodipine group, and combined CVD in the lisinopril arm occurred more commonly than in the chlorthalidone group by $38 \%$ and $10 \%$, respectively $(P<0.05)$. This was perhaps due to chlorthalidone causing a slightly lower, but significant, systolic BP than amlodipine and lisinopril. Similar results were seen in patients with and without diabetes. Overall, the three antihypertensive drug classes, ACEi, CCB and thiazide, were equivalent in decreasing combined fatal CHD and nonfatal MI in high risk patients with diabetes.

INSIGHT $^{79}(\mathrm{~N}=6321)$ compared the dihydropyridine CCB nifedipine with diuretics, and NORDIL ${ }^{80}(\mathrm{~N}=10881)$ evaluated the non-dihydropyridine $\mathrm{CCB}$ diltiazem versus diuretic or $\beta$-blocker based therapies in preventing $\mathrm{CV}$ events in patients with hypertension. In both studies, diabetes was present in $20.6 \%$ and $6.5 \%$ of participants, respectively. Participants were followed for a period of 4 to 5 years. No major differences in final BP values or in combined primary outcomes of $\mathrm{CV}$ deaths, stroke, or MIs were seen between interventional groups.

INVEST $^{81}$ was a shorter duration study that compared the efficacy of non-dihydropyridine $\mathrm{CCB}$ verapamil against $\beta$-blocker atenolol in preventing $\mathrm{CV}$ events in patients with 
hypertension and CAD. Primary end-points were occurrence of nonfatal MI, nonfatal stroke, or death from any cause. At enrollment, 28\% of 22576 subjects had diabetes. After 2.7 years of follow up, no significant differences in BP measurements or primary outcomes were detected between the two groups.

In conclusion, ALLHAT, ${ }^{78}$ INSIGHT, ${ }^{79}$ NORDIL $^{80}$ and INVEST $^{81}$ show that CCB (dihydropyridine or nondihydropyridine), thiazide diuretic and $\beta$-blocker are overall equivalent in lowering $\mathrm{BP}$ and rate of $\mathrm{CV}$ events in individuals with diabetes. By extrapolation, one could infer that any of the three classes can be added to the initial ACEi or ARB antihypertensive therapy. For those intolerant of ACEi or $\mathrm{ARB}$, a CCB, thiazide or $\beta$-blocker could be used as first-line treatment of high BP in patients with diabetes.

\section{A case for $C C B$ as second-line therapy}

More reliable data in choosing the second-line antihypertensive therapy after ACEi or ARB in patients with diabetes come from ACCOMPLISH ${ }^{82}$ and GUARD ${ }^{83}$ randomized trials. ACCOMPLISH evaluated if ACEi + CCB (benazepril + amlodipine) was superior to ACEi + hydrochlorothiazide (benazepril + HCTZ) combination therapy in preventing $\mathrm{CV}$ events in subjects with mean BP 145/80 mmHg and established MI, CAD, previous coronary revascularization or stroke. At study entry, 60\% of 11,506 participants had diabetes. Primary outcome was the occurrence of $\mathrm{CV}$ death, MI, stroke, hospitalization from angina, coronary revascularization, or resuscitation after sudden cardiac arrest.

The trial was terminated early at 3 years due to clear benefits in the benazapril + amlodipine arm: ACEi + CCB combination group achieved a lower BP $(\Delta 0.9 / \Delta 1.1 \mathrm{mmHg}$, $P<0.001)$ and $20 \%$ greater reduction $(P<0.001)$ in composite primary outcomes than the ACEi $+\mathrm{HCTZ}$ arm. Similar results were noted among patients with diabetes. However, for renal outcomes in individuals with diabetes, secondary analysis revealed that serum creatinine doubling or ESRD occurred similarly in both interventional groups $(\mathrm{HR}=0.78$, $P<0.48) .{ }^{84}$

In contrary, the smaller study GUARD ${ }^{83}$ showed that the same ACEi + CCB combined therapy used in ACCOM$\mathrm{PLISH}^{82}$ could be more beneficial than ACEi + HCTZ regimen in preventing diabetic nephropathy. At enrollment, 332 subjects with diabetes, albuminuria and mean BP 151/88 $\mathrm{mmHg}$ received either the benazepril + amlodipine or benazepril + HCTZ combination therapy. After 1 year of follow up, individuals treated with ACEi + CCB achieved a lower diastolic BP $(\Delta 2 \mathrm{mmHg}, P<0.05)$ and higher
GFR $(\Delta 11.6 \mathrm{~mL} / \mathrm{min}, P<0.05)$ than those receiving the $\mathrm{ACEi}+\mathrm{HCTZ}$ regimen.

It is worth noting that dihydropyridine and nondihydropyridine CCB seem to be equivalent in reducing albuminuria and BP in diabetic individuals. ${ }^{85}$ Indirect evidence also suggests their similarity in preventing CV outcomes in persons with diabetes. ${ }^{78-81}$ In conclusion, ACCOMPLISH ${ }^{82}$ and GUARD ${ }^{83}$ suggest that a dihydropyridine CCB could be a better second-line agent than a diuretic thiazide in lowering $\mathrm{BP}$ and risk of CV disease in individuals with hypertension and type 2 diabetes. However, its relative benefit in preventing diabetic nephropathy is somewhat inconsistent.

\section{Aldosterone antagonists, renin inhibitor and $\alpha$-blockers}

Aldosterone antagonists, renin inhibitor and $\alpha$-blockers can also be utilized to bring BP to goal in patients with type 2 diabetes. Unfortunately no significant comparative data of these agents with $\mathrm{ACEi}, \mathrm{ARB}, \mathrm{CCB}$, diuretics or $\beta$-blockers are available in persons with diabetes. The one exception is $\alpha$-blocker doxazosin, which increased the incidence of HF more than diuretic chlorthalidone in participants of the ALLHAT trial. ${ }^{78}$

Evidence suggests that aldosterone antagonists could be critical in treating diabetic individuals with resistant hypertension - defined by the use of $\geq 3$ BP-lowering drugs. For example, in the observational study ASCOT-BPLA, ${ }^{86}$ spironolactone 25 to $50 \mathrm{mg} /$ day reduced the BP markedly by $\Delta 22 / \Delta 9 \mathrm{mmHg}$ in 1411 subjects with refractory hypertension over a 1.3-year period. In another observational trial of 7 to 15 months' duration, spironolactone 25 to $100 \mathrm{mg}$ /day lowered BP by $\Delta 16 / \Delta 9 \mathrm{mmHg}(P<0.001)$ in 175 subjects with resistant high $\mathrm{BP}^{87}$ In both studies, diabetes was present in $40 \%$ and $33 \%$ of participants, respectively. It is worth noting that about $15 \%$ of individuals with type 2 diabetes and refractory hypertension have primary hyperaldosteronism, ${ }^{88}$ for which aldosterone antagonist spironolactone or eplerenone would be an ideal therapy.

The renin inhibitor aliskiren, the newest antihypertensive drug class, could be renoprotective apart from its BPlowering effect in persons with diabetes. For example, in the AVOID ${ }^{89}$ trial, 599 subjects with type 2 diabetes, mean BP 135/78 mmHg and baseline macroalbuminuria - already treated with the ARB losartan $100 \mathrm{mg} /$ day - were randomized to receive aliskiren $300 \mathrm{mg} /$ day or placebo. After 6 months of follow up, the renin inhibitor reduced proteinuria $20 \%$ more than placebo $(P<0.001)$. This outcome was independent of the antihypertensive effect of aliskiren. 
In conclusion, aldosterone antagonists, renin inhibitor and $\alpha$-blockers can be added to mainstream therapies of ACEi, $\mathrm{ARB}, \mathrm{CCB}$, diuretics or $\beta$-blockers, if necessary, to reduce $\mathrm{BP}$ to $<130 / 80 \mathrm{mmHg}$ in patients with type 2 diabetes.

\section{Fixed combination therapy improves BP control}

One method to improve adherence and reduce clinical inertia among individuals with diabetes and hypertension is to offer a 2-drug fixed dose combination therapy. This is a good rationale since most patients will require more than one drug class to reduce BP to goal. ${ }^{18,36,43}$

The best evidence comes from ADVANCE ${ }^{90}$ trial, which examined if fixed ACEi + thiazide (perindopril + indapamide) treatment was superior to other antihypertensive regimens in lowering vascular complications in subjects $(\mathrm{N}=11140)$ with type 2 diabetes and mean BP 145/81 mmHg. Primary outcome was the occurrence of combined micro- and macrovascular complications - defined by CV death, nonfatal MI, nonfatal stroke, retinopathy and nephropathy.

After 4.3 years of follow up, the fixed perindopril + indapamide group experienced a lower BP $(\Delta 5.6 / \Delta 2.2 \mathrm{mmHg}$, $P<0.05)$ and less composite primary outcomes $(\Delta 9 \%$, $P<0.05)$ than the control arm. In regard to secondary end points, the fixed ACEi+Thiazide group also experienced significantly fewer CVD and deaths from any cause than its counterpart by $18 \%$ and $14 \%$ respectively.

Results of two smaller randomized trials also support the beneficial use of fixed dose combination therapy for treatment of hypertension in type 2 diabetes. In the PREMIER ${ }^{91}$ study, 481 subjects with diabetes, mean BP 158/93 mmHg and albuminuria were randomized to receive fixed ACEi + thiazide (perindopril + indapamide) therapy or ACEi (enalapril) alone. Medication doses were increased based on BP response. Primary outcome was the difference in the albumin excretion rate and supine BP measurements. After 12 months of follow up, the fixed perindopril + indapamide group achieved a lower BP $(\Delta 3 / \Delta 1.5 \mathrm{mmHg}, P<0.05)$ and less urinary albumin excretion than the enalapril arm.

In the SHIELD ${ }^{92}$ trial, 214 individuals with diabetes and mean BP 156/97 mmHg were randomized to receive either fixed ACEi + CCB (benazepril + amlodipine) therapy or ACEi (enalapril) alone. Medication doses were increased in both groups if $\mathrm{BP} \geq 130 / 80 \mathrm{mmHg}$. At 3 months, $63 \%$ of subjects in the fixed ACEi + CCB therapy group had achieved the BP goal compared to only $37 \%$ of those treated with enalapril. The difference was statistically significant $(P=0.002)$.
In summary, early initiation of 2-drug fixed dose combination therapy with $\mathrm{ACEi}+\mathrm{CCB}$ or thiazide improves BP control more than monotherapy in patients with hypertension and diabetes.

\section{Recommendations}

Hypertension is not only the main contributor of increased CV morbidity and mortality in patients with type 2 diabetes, but also the least controlled variable compared to hyperglycemia and dyslipidemia risk factors. ${ }^{35-37}$ This calls for an aggressive approach in reducing BP under 130/80 $\mathrm{mmHg}$ in all individuals with diabetes. Perhaps a lower target might be considered in the future. ${ }^{29,30}$ Similar to guidelines by several major organizations, ${ }^{24-28}$ we recommend that if BP is persistently $\geq 130 / 80 \mathrm{mmHg}$, then life-style intervention should be initiated. However, if $\mathrm{BP} \geq 140 / 90 \mathrm{mmHg}$, pharmacotherapy must be started as well.

Life-style changes that reduce $\mathrm{BP}^{93}$ are low sodium diet $<1.5 \mathrm{~g} /$ day ${ }^{94}$ increased potassium intake $>4.7 \mathrm{~g} /$ day, $\mathrm{BMI}<25 \mathrm{~kg} / \mathrm{m}^{2}$, weight loss by $>4.5$ to $5.0 \mathrm{~kg},{ }^{95,96}$ increased intake of fruits and vegetables ( 8 to 10 servings/day), decreased consumption of dairy products that are rich in fat ( 2 to 3 servings/day), avoidance of excessive alcohol use ( $\leq 2 \mathrm{drinks} /$ day/men and $\leq 1 \mathrm{drink} /$ day/women) and increased physical activity. ${ }^{96,97}$ Studies in patients without diabetes have shown that these measures are equivalent to drug monotherapy for mild hypertension. ${ }^{94}$ But unlike medication monotherapy, life-style interventions in the form of exercise and weight loss could help control other aspects of diabetes such as hyperglycemia and dyslipidemia.

If life-style changes are unsuccessful or BP $\geq 140$ / $90 \mathrm{mmHg}$ then pharmacotherapy should be added immediately. Beta-blocker must be given to all patients with established CAD or MI. ${ }^{98}$ In Figure 1 we present 2 different protocols based on initial BP value. In the first, when BP is $130 / 80$ to 140/90 $\mathrm{mmHg}$, we advise first-line monotherapy with either an ACEi or ARB, depending on availability, cost and tolerability. Equivalence of ARB with ACEi was documented in the trials DETAIL, ${ }^{73}$ ONTARGET $^{75}$ and VALIANT. ${ }^{76}$

In the second protocol, when $\mathrm{BP}$ is $\geq 140 / 90 \mathrm{mmHg}$, we recommend starting a low-dose fixed combination regimen containing either ACEi or ARB. Here we also consider patient adherence, clinical inertia and the fact that most individuals will require 2 or more drugs to control their hypertension. Early initiation of combined therapy is increasingly recommended for glucose management as well. ${ }^{99}$ Based on indirect evidence from SCOPE, ${ }^{70}$ VALUE, ${ }^{71}$ and TRANSCEND, ${ }^{72}$ one could favor treatment with ACEi over ARB. Given the 


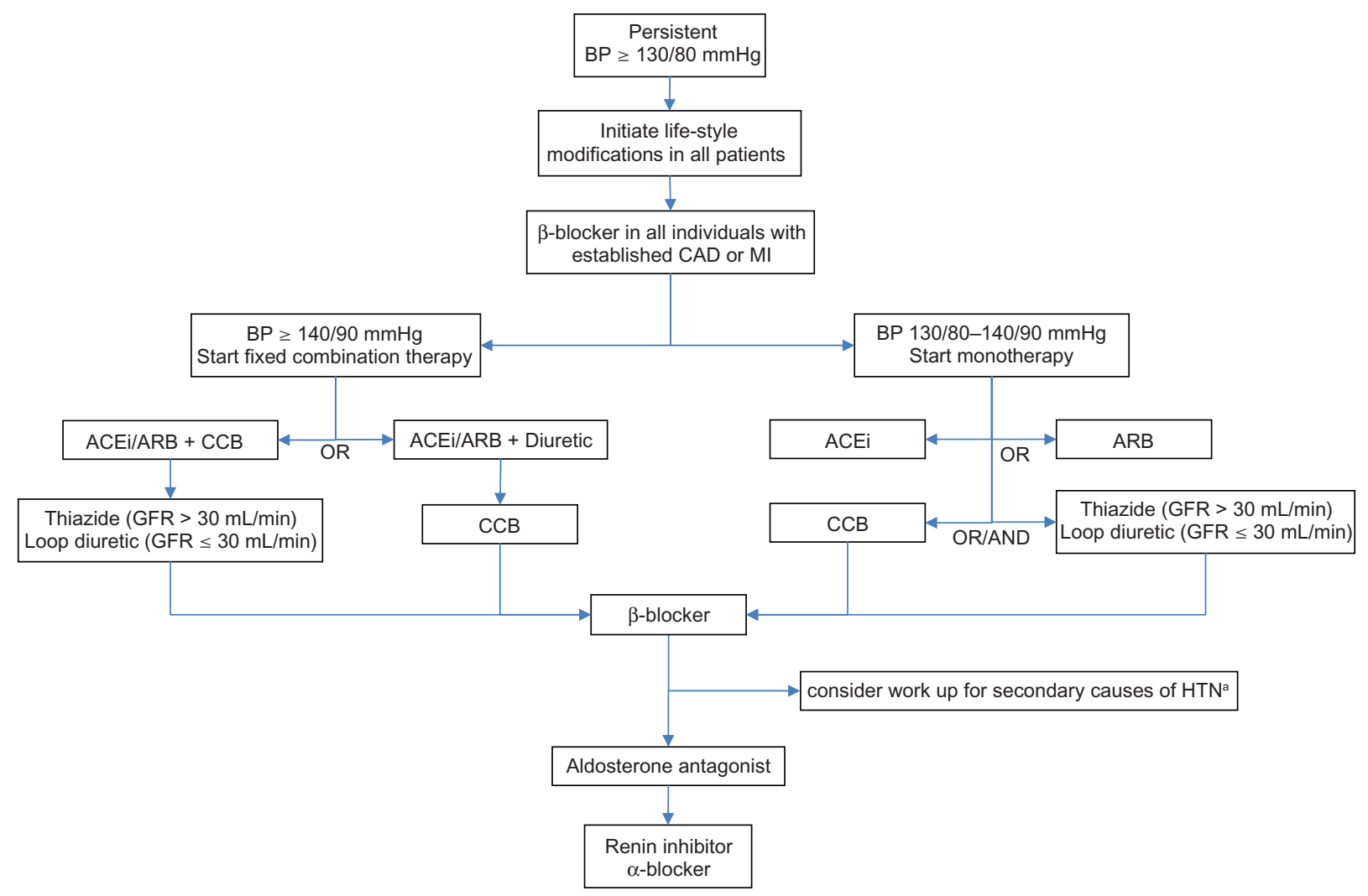

Figure I Algorithm for treatment of hypertension in inividuals with diabetes. Maximize dose before starting the next drug. First line $=$ ACEi or ARB (equivalence seen in DETAIL ${ }^{73}$ ONTARGET $^{75}$ and VALIANT ${ }^{76}$ ).

- Both reduce microalbuminuria and rate of nephropathy independently of their antihypertensive effect.

- ACEi preferred over ARB (indirect evidence for cardiovascular outcomes; SCOPE, ${ }^{70}$ VALUE $^{71}$ and TRANSCEND ${ }^{72}$ ).

- Recommend against concomitant use of ARB with ACEi (ONTARGET ${ }^{75}$ and VALIANT ${ }^{76}$ ). Second line $=$ CCB or diuretic

- Dihydropyridine CCB favored over diuretic (ACCOMPLISH ${ }^{82}$ and GUARD ${ }^{83}$ ) or in the presence of electrolyte anomalies.

- Diuretic preferred in heart failure or edematous conditions.

- Loop diuretic recommended if GFR $\leq 30 \mathrm{~mL} / \mathrm{min}$ due to marked state of fluid overload.

- If needed, CCB and diuretic can be combined.

Third line $=\beta$-blocker, primarily due to side effect profile. However, it is indicated in all patients with established CAD and MI.

Fourth line $=$ Aldosterone antagonist $\left(\right.$ ASCOT-BPLA $\left.{ }^{86}\right)$.

Fifth line $=$ Renin inhibitor or $\alpha$-blocker, not enough comparative data from clinical trials for clear recommendation.

Peripheral $\alpha$-blocker, due to orthostatic hypotension and results of ALLHAT. ${ }^{78}$ It could be used earlier in patients with symptomatic BPH.

arenal artery stenosis, hyperaldosteronism, Cushing's syndrome or pheochromocytoma.

Abbreviations: BP, blood pressure; $\mathrm{ACEi}$, angiotensin converting enzyme inhibitor; ARB, angiotensin receptor blocker; CCB, calcium channel blocker; CAD, coronary artery disease; MI, myocardial infarction; HTN, hypertension; GFR, glomerular filtration rate; BPH, benign prostate hyperplasia.

results of ONTARGET ${ }^{75}$ and VALIANT, ${ }^{76}$ we advise against concomitant use of ACEi with ARB, since together they cause significantly higher rates of adverse events without additional benefits.

In both protocols, for second-line therapy we suggest using dihydropyridine $\mathrm{CCB}$ over diuretics, based on outcomes from ACCOMPLISH ${ }^{82}$ and GUARD. ${ }^{83}$ The choice would also depend on relative contraindications of each drug class. For example, a CCB is favored over a thiazide in an individual with electrolyte anomalies but less so in someone who suffers from HF or edematous conditions. A loop diuretic is recommended over a thiazide if GFR $\leq 30 \mathrm{~mL} / \mathrm{min}$ due to patients' state of fluid overload. The dose of medications must be increased or maximized based on $\mathrm{BP}$ response. If $\mathrm{BP}$ is still uncontrolled then we recommend adding either a CCB or diuretic, whichever is not part of the current combination therapy.

If BP goal is not achieved, we suggest adding a $\beta$-blocker. We chose $\beta$-blockers to be third-line agents primarily due to poor side effect profile of bradycardia and worsening of insulin resistance, ${ }^{100,101}$ although UKPDS, ${ }^{18}$ NORDIL $^{80}$ and INVEST ${ }^{81}$ clearly show their equivalence to ACEi and CCB. At this point we also consider screening for secondary causes of hypertension like renal artery stenosis, hyperaldosteronism, ${ }^{88}$ Cushing's syndrome or pheochromocytoma.

As a fourth-line therapy, we choose aldosterone antagonists due to their BP-lowering potency, revealed in the ASCOT-BPLA ${ }^{86}$ trial. Finally, the renin inhibitors and $\alpha$-blockers can also be utilized, if necessary, to control BP 
in persons with diabetes. We advise peripheral $\alpha$-blockers to be a last-line therapeutic option based on results of ALL$\mathrm{HAT}^{78}$ and their propensity to cause orthostatic hypotension - although they could be used earlier in someone with benign prostate hyperplasia.

In conclusion, hypertension continues to be a key determinant of morbidity and mortality in type 2 diabetes. Despite clear evidence for a BP goal $<130 / 80 \mathrm{mmHg}$, most patients do not achieve optimal results. Early initiation of fixed-dose combination therapy and aggressive titration of medications can improve patient adherence, reduce clinical inertia and bring BP to target, thereby reducing both micro- and macrovascular complications in individuals with diabetes.

\section{Disclosures}

The authors report no conflicts of interest in this work.

\section{References}

1. Huang ES, Basu A, O’Grady M, Capretta JC. Projecting the future diabetes population size and related costs for the U.S. Diabetes Care. 2009;32(12):2225-2229.

2. Wild S, Roglic G, Green A, Sicree R, King H. Global prevalence of diabetes: estimates for the year 2000 and projections for 2030. Diabetes Care. 2004;27(5):1047-1053.

3. Haffner SM, Lehto S, Ronnemaa T, Pyorala K, Laakso M. Mortality from coronary heart disease in subjects with type 2 diabetes and in nondiabetic subjects with and without prior myocardial infarction. N Engl J Med. 1998;339(4):229-234.

4. Kannel WB, McGee DL. Diabetes and cardiovascular disease. The Framingham study. JAMA. 1979;241(19):2035-2038.

5. Manson JE, Colditz GA, Stampfer MJ, et al. A prospective study of maturity-onset diabetes mellitus and risk of coronary heart disease and stroke in women. Arch Intern Med. 1991;151(6): $1141-1147$.

6. Laakso M. Hyperglycemia and cardiovascular disease in type 2 diabetes. Diabetes. 1999;48(5):937-942.

7. Sowers JR, Epstein M. Diabetes mellitus and associated hypertension, vascular disease, and nephropathy. An update. Hypertension. 1995; 26(6 Pt 1):869-879.

8. Molitch ME, DeFronzo RA, Franz MJ, et al. Nephropathy in diabetes. Diabetes Care. 2004;27 Suppl 1:S79-S83.

9. Ciulla TA, Amador AG, Zinman B. Diabetic retinopathy and diabetic macular edema: pathophysiology, screening, and novel therapies. Diabetes Care. 2003;26(9):2653-2664.

10. Simonson DC. Etiology and prevalence of hypertension in diabetic patients. Diabetes Care. 1988;11(10):821-827.

11. Hypertension in Diabetes Study (HDS): I. Prevalence of hypertension in newly presenting type 2 diabetic patients and the association with risk factors for cardiovascular and diabetic complications. J Hypertens. 1993;11(3):309-317.

12. Mortality findings for stepped-care and referred-care participants in the hypertension detection and follow-up program, stratified by other risk factors. The Hypertension Detection and Follow-up Program Cooperative Research Group. Prev Med. 1985;14(3):312-335.

13. Hypertension in Diabetes Study (HDS): II. Increased risk of cardiovascular complications in hypertensive type 2 diabetic patients. J Hypertens. 1993;11(3):319-325.

14. Turner RC, Millns H, Neil HA, et al. Risk factors for coronary artery disease in non-insulin dependent diabetes mellitus: United Kingdom Prospective Diabetes Study (UKPDS: 23). BMJ. 1998; 316(7134):823-828.
15. Mehler PS, Jeffers BW, Estacio R, Schrier RW. Associations of hypertension and complications in non-insulin-dependent diabetes mellitus. Am J Hypertens. 1997;10(2):152-161.

16. Schrier RW, Estacio RO, Esler A, Mehler P. Effects of aggressive blood pressure control in normotensive type 2 diabetic patients on albuminuria, retinopathy and strokes. Kidney Int. 2002;61(3):1086-1097.

17. Kohner EM, Aldington SJ, Stratton IM, et al. United Kingdom Prospective Diabetes Study, 30: diabetic retinopathy at diagnosis of non-insulin-dependent diabetes mellitus and associated risk factors. Arch Ophthalmol. 1998;116(3):297-303.

18. Tight blood pressure control and risk of macrovascular and microvascular complications in type 2 diabetes: UKPDS 38. UK Prospective Diabetes Study Group. BMJ. 1998;317(7160):703-713.

19. Holman RR, Paul SK, Bethel MA, Neil HA, Matthews DR. Long-term follow-up after tight control of blood pressure in type 2 diabetes. N Engl J Med. 2008;359(15):1565-1576.

20. Curb JD, Pressel SL, Cutler JA, et al. Effect of diuretic-based antihypertensive treatment on cardiovascular disease risk in older diabetic patients with isolated systolic hypertension. Systolic Hypertension in the Elderly Program Cooperative Research Group. JAMA. 1996;276(23):1886-1892.

21. Tuomilehto J, Rastenyte D, Birkenhager WH, et al. Effects of calcium-channel blockade in older patients with diabetes and systolic hypertension. Systolic Hypertension in Europe Trial Investigators. N Engl J Med. 1999;340(9):677-684.

22. Hansson L, Zanchetti A, Carruthers SG, et al. Effects of intensive blood-pressure lowering and low-dose aspirin in patients with hypertension: principal results of the Hypertension Optimal Treatment (HOT) randomised trial. HOT Study Group. Lancet. 1998;351(9118): $1755-1762$.

23. Effects of ramipril on cardiovascular and microvascular outcomes in people with diabetes mellitus: results of the HOPE study and MICRO-HOPE substudy. Heart Outcomes Prevention Evaluation Study Investigators. Lancet. 2000;355(9200):253-259.

24. Ryden L, Standl E, Bartnik M, et al. Guidelines on diabetes, prediabetes, and cardiovascular diseases: executive summary. The Task Force on Diabetes and Cardiovascular Diseases of the European Society of Cardiology (ESC) and of the European Association for the Study of Diabetes (EASD). Eur Heart J. 2007;28(1):88-136.

25. Rosendorff C, Black HR, Cannon CP, et al. Treatment of hypertension in the prevention and management of ischemic heart disease: a scientific statement from the American Heart Association Council for High Blood Pressure Research and the Councils on Clinical Cardiology and Epidemiology and Prevention. Circulation. 2007;115(21): 2761-2788.

26. Chobanian AV, Bakris GL, Black HR, et al. Seventh report of the Joint National Committee on Prevention, Detection, Evaluation, and Treatment of High Blood Pressure. Hypertension. 2003;42(6): $1206-1252$.

27. K/DOQI clinical practice guidelines for chronic kidney disease: evaluation, classification, and stratification. Am J Kidney Dis. 2002;39 (2 Suppl 1):S1-S266.

28. Executive summary: Standards of medical care in diabetes -2010 . Diabetes Care. ;33 Suppl 1:S4-S10.

29. Adler AI, Stratton IM, Neil HA, et al. Association of systolic blood pressure with macrovascular and microvascular complications of type 2 diabetes (UKPDS 36): prospective observational study. $B M J$. 2000;321(7258):412-419.

30. Estacio RO, Coll JR, Tran ZV, Schrier RW. Effect of intensive blood pressure control with valsartan on urinary albumin excretion in normotensive patients with type 2 diabetes. Am J Hypertens. 2006;19(12): 1241-1248.

31. Mogensen CE. Microalbuminuria predicts clinical proteinuria and early mortality in maturity-onset diabetes. NEngl J Med. 1984;310(6): 356-360.

32. Gerstein HC, Mann JF, Yi Q, et al. Albuminuria and risk of cardiovascular events, death, and heart failure in diabetic and nondiabetic individuals. JAMA. 2001;286(4):421-426. 
33. Mattock MB, Morrish NJ, Viberti G, Keen H, Fitzgerald AP, Jackson G. Prospective study of microalbuminuria as predictor of mortality in NIDDM. Diabetes. 1992;41(6):736-741.

34. Godley PJ, Maue SK, Farrelly EW, Frech F. The need for improved medical management of patients with concomitant hypertension and type 2 diabetes mellitus. Am J Manag Care. 2005;11(4):206-210.

35. Gudbjornsdottir S, Eeg-Olofsson K, Cederholm J, Zethelius B, Eliasson B, Nilsson PM. Risk factor control in patients with Type 2 diabetes and coronary heart disease: findings from the Swedish National Diabetes Register (NDR). Diabet Med. 2009;26(1):53-60.

36. Mann DM, Woodward M, Ye F, Krousel-Wood M, Muntner P. Trends in medication use among US adults with diabetes mellitus: glycemic control at the expense of controlling cardiovascular risk factors. Arch Intern Med. 2009;169(18):1718-1720.

37. McFarlane SI, Jacober SJ, Winer N, et al. Control of cardiovascular risk factors in patients with diabetes and hypertension at urban academic medical centers. Diabetes Care. 2002;25(4):718-723.

38. McLean DL, Simpson SH, McAlister FA, Tsuyuki RT. Treatment and blood pressure control in 47,964 people with diabetes and hypertension: a systematic review of observational studies. Can J Cardiol. 2006;22(10):855-860.

39. Prevost G, Phan TM, Mounier-Vehier C, Fontaine P. Control of cardiovascular risk factors in patients with type 2 diabetes and hypertension in a French national study (Phenomen). Diabetes Metab. 2005;31(5):479-485.

40. Raum E, Lietzau S, Stegmaier C, Brenner H, Rothenbacher D. For the majority of patients with diabetes blood pressure and lipid management is not in line with recommendations. Results from a large population-based cohort in Germany. Pharmacoepidemiol Drug Saf. 2008;17(5):485-494.

41. Bertholet N, Favrat B, Fallab-Stubi CL, Brunner HR, Burnier M. Why Objective Monitoring of Compliance is Important in the Management of Hypertension. J Clin Hypertens (Greenwich). 2000;2(4):258-262.

42. Cramer JA, Benedict A, Muszbek N, Keskinaslan A, Khan ZM. The significance of compliance and persistence in the treatment of diabetes, hypertension and dyslipidaemia: a review. Int J Clin Pract. 2008;62(1):76-87.

43. Zidek W, Naditch-Brule L, Perlini S, Farsang C, Kjeldsen SE. Blood pressure control and components of the metabolic syndrome: the GOOD survey. Cardiovasc Diabetol. 2009;8:51.

44. Stuckey HL, Dellasega C, Graber NJ, Mauger DT, Lendel I, Gabbay RA. Diabetes nurse case management and motivational interviewing for change (DYNAMIC): study design and baseline characteristics in the Chronic Care Model for type 2 diabetes. Contemp Clin Trials. 2009;30(4):366-374.

45. Gabbay RA, Durdock K. The use of motivational interviewing to improve elderly diabetic patient's adherence to treatment recommendations. In: Lignalli AT, ed. Handbook of Type 2 Diabetes in the Middle Aged and Elderly: Nova Science; 2009:57-68.

46. Schroeder K, Fahey T, Ebrahim S. How can we improve adherence to blood pressure-lowering medication in ambulatory care? Systematic review of randomized controlled trials. Arch Intern Med. 2004;164(7): 722-732.

47. Phillips LS, Branch WT, Cook CB, et al. Clinical inertia. Ann Intern Med. 2001;135(9):825-834.

48. Kerr EA, Zikmund-Fisher BJ, Klamerus ML, Subramanian U, Hogan MM, Hofer TP. The role of clinical uncertainty in treatment decisions for diabetic patients with uncontrolled blood pressure. Ann Intern Med. 2008;148(10):717-727.

49. Gil-Guillén V, Orozco-Beltrán D, Pérez RP, et al. Clinical inertia in diagnosis and treatment of hypertension in primary care: Quantification and associated factors. Blood Press. 2010;19(1):3-10.

50. Khan L, Mincemoyer S, Gabbay RA. Diabetes registries: where we are and where are we headed? Diabetes Technol Ther. 2009;11(4):255-262.

51. Improvingchroniccare.org [homepage on the Internet]. The chronic care model [updated 2009].http://www.improvingchroniccare.org/. Accessed April 28, 2010.
52. Ruggenenti P, Fassi A, Ilieva AP, et al. Preventing microalbuminuria in type 2 diabetes. N Engl J Med. 2004;351(19):1941-1951.

53. Hansson L, Lindholm LH, Niskanen L, et al. Effect of angiotensinconverting-enzyme inhibition compared with conventional therapy on cardiovascular morbidity and mortality in hypertension: the Captopril Prevention Project (CAPPP) randomised trial. Lancet. 1999;353(9153): 611-616.

54. Niskanen L, Hedner T, Hansson L, Lanke J, Niklason A. Reduced cardiovascular morbidity and mortality in hypertensive diabetic patients on first-line therapy with an ACE inhibitor compared with a diuretic/ beta-blocker-based treatment regimen: a subanalysis of the Captopril Prevention Project. Diabetes Care. 2001;24(12):2091-2096.

55. Ahmad J, Siddiqui MA, Ahmad H. Effective postponement of diabetic nephropathy with enalapril in normotensive type 2 diabetic patients with microalbuminuria. Diabetes Care. 1997;20(10):1576-1581.

56. Lewis EJ, Hunsicker LG, Bain RP, Rohde RD. The effect of angiotensin-converting-enzyme inhibition on diabetic nephropathy. The Collaborative Study Group. N Engl J Med. 1993;329(20):1456-1462.

57. Ravid M, Brosh D, Levi Z, Bar-Dayan Y, Ravid D, Rachmani R. Use of enalapril to attenuate decline in renal function in normotensive, normoalbuminuric patients with type 2 diabetes mellitus. A randomized, controlled trial. Ann Intern Med. 1998;128(12 Pt 1):982-988.

58. Ravid M, Lang R, Rachmani R, Lishner M. Long-term renoprotective effect of angiotensin-converting enzyme inhibition in non-insulindependent diabetes mellitus. A 7-year follow-up study. Arch Intern Med. 1996;156(3):286-289.

59. Sano T, Kawamura T, Matsumae H, et al. Effects of long-term enalapril treatment on persistent micro-albuminuria in well-controlled hypertensive and normotensive NIDDM patients. Diabetes Care. 1994;17(5):420-424.

60. Bosch J, Lonn E, Pogue J, Arnold JM, Dagenais GR, Yusuf S. Longterm effects of ramipril on cardiovascular events and on diabetes: results of the HOPE study extension. Circulation. 2005;112(9):1339-1346.

61. Wing LM, Reid CM, Ryan P, et al. A comparison of outcomes with angiotensin-converting - enzyme inhibitors and diuretics for hypertension in the elderly. N Engl J Med. 2003;348(7):583-592.

62. Estacio RO, Jeffers BW, Hiatt WR, Biggerstaff SL, Gifford N, Schrier RW. The effect of nisoldipine as compared with enalapril on cardiovascular outcomes in patients with non-insulin-dependent diabetes and hypertension. N Engl J Med. 1998;338(10):645-652.

63. Hansson L, Lindholm LH, Ekbom T, et al. Randomised trial of old and new antihypertensive drugs in elderly patients: cardiovascular mortality and morbidity the Swedish Trial in Old Patients with Hypertension-2 study. Lancet. 1999;354(9192):1751-1756.

64. Tatti P, Pahor M, Byington RP, et al. Outcome results of the Fosinopril Versus Amlodipine Cardiovascular Events Randomized Trial (FACET) in patients with hypertension and NIDDM. Diabetes Care. 1998;21(4):597-603.

65. Brenner BM, Cooper ME, de Zeeuw D, et al. Effects of losartan on renal and cardiovascular outcomes in patients with type 2 diabetes and nephropathy. N Engl J Med. 2001;345(12):861-869.

66. Lewis EJ, Hunsicker LG, Clarke WR, et al. Renoprotective effect of the angiotensin-receptor antagonist irbesartan in patients with nephropathy due to type 2 diabetes. $N$ Engl J Med. 2001;345(12):851-860.

67. Parving HH, Lehnert H, Brochner-Mortensen J, Gomis R, Andersen S, Arner P. The effect of irbesartan on the development of diabetic nephropathy in patients with type 2 diabetes. $N$ Engl J Med. 2001;345(12):870-878.

68. Mann JF, Schmieder RE, Dyal L, et al. Effect of telmisartan on renal outcomes: a randomized trial. Ann Intern Med. 2009;151(1):1-10, W11-W12.

69. Dahlof B, Devereux RB, Kjeldsen SE, et al. Cardiovascular morbidity and mortality in the Losartan Intervention For Endpoint reduction in hypertension study (LIFE): a randomised trial against atenolol. Lancet. 2002;359(9311):995-1003.

70. Lithell H, Hansson L, Skoog I, et al. The Study on Cognition and Prognosis in the Elderly (SCOPE): principal results of a randomized double-blind intervention trial. J Hypertens. 2003;21(5):875-886. 
71. Julius S, Kjeldsen SE, Weber M, et al. Outcomes in hypertensive patients at high cardiovascular risk treated with regimens based on valsartan or amlodipine: the VALUE randomised trial. Lancet. 2004;363(9426):2022-2031.

72. Yusuf S, Teo K, Anderson C, et al. Effects of the angiotensin-receptor blocker telmisartan on cardiovascular events in high-risk patients intolerant to angiotensin-converting enzyme inhibitors: a randomised controlled trial. Lancet. 2008;372(9644):1174-1183.

73. Barnett AH, Bain SC, Bouter P, et al. Angiotensin-receptor blockade versus converting-enzyme inhibition in type 2 diabetes and nephropathy. $N$ Engl J Med. 2004;351(19):1952-1961.

74. Lacourciere Y, Belanger A, Godin C, et al. Long-term comparison of losartan and enalapril on kidney function in hypertensive type 2 diabetics with early nephropathy. Kidney Int. 2000;58(2):762-769.

75. Yusuf S, Teo KK, Pogue J, et al. Telmisartan, ramipril, or both in patients at high risk for vascular events. $N$ Engl J Med. 2008;358(15):1547-1559.

76. Pfeffer MA, McMurray JJ, Velazquez EJ, et al. Valsartan, captopril, or both in myocardial infarction complicated by heart failure, left ventricular dysfunction, or both. N Engl J Med. 2003;349(20):1893-1906.

77. Mann JF, Schmieder RE, McQueen M, et al. Renal outcomes with telmisartan, ramipril, or both, in people at high vascular risk (the ONTARGET study): a multicentre, randomised, double-blind, controlled trial. Lancet. 2008;372(9638):547-553.

78. Major outcomes in high-risk hypertensive patients randomized to angiotensin-converting enzyme inhibitor or calcium channel blocker vs diuretic: The Antihypertensive and Lipid-Lowering Treatment to Prevent Heart Attack Trial (ALLHAT). JAMA. 2002;288(23):2981-2997.

79. Brown MJ, Palmer CR, Castaigne A, et al. Morbidity and mortality in patients randomised to double-blind treatment with a long-acting calcium-channel blocker or diuretic in the International Nifedipine GITS study: Intervention as a Goal in Hypertension Treatment (INSIGHT). Lancet. 2000;356(9227):366-372.

80. Hansson L, Hedner T, Lund-Johansen P, et al. Randomised trial of effects of calcium antagonists compared with diuretics and beta-blockers on cardiovascular morbidity and mortality in hypertension: the Nordic Diltiazem (NORDIL) study. Lancet. 2000;356(9227): 359-365.

81. Pepine CJ, Handberg EM, Cooper-DeHoff RM, et al. A calcium antagonist vs a non-calcium antagonist hypertension treatment strategy for patients with coronary artery disease. The International VerapamilTrandolapril Study (INVEST): a randomized controlled trial. JAMA. 2003;290(21):2805-2816.

82. Jamerson K, Weber MA, Bakris GL, et al. Benazepril plus amlodipine or hydrochlorothiazide for hypertension in high-risk patients. $N \mathrm{Engl}$ J Med. 2008;359(23):2417-2428.

83. Bakris GL, Toto RD, McCullough PA, Rocha R, Purkayastha D, Davis P. Effects of different ACE inhibitor combinations on albuminuria: results of the GUARD study. Kidney Int. 2008;73(11): 1303-1309.

84. Bakris GL, Sarafidis PA, Weir MR, Dahlof B, Pitt B, Jamerson K. Renal Outcomes with different fixed-dose combination therapies in patients with hypertension at high risk for cardiovascular events (ACCOMPLISH): a prespecified secondary analysis of a randomized controlled trial. Lancet. 2010; Published online February 18, 2010, www.thelancet.com

85. Bakris GL, Weir MR, Secic M, Campbell B, Weis-McNulty A. Differential effects of calcium antagonist subclasses on markers of nephropathy progression. Kidney Int. 2004;65(6):1991-2002.
86. Chapman N, Dobson J, Wilson S, et al. Effect of spironolactone on blood pressure in subjects with resistant hypertension. Hypertension. 2007;49(4):839-845.

87. de Souza F, Muxfeldt E, Fiszman R, Salles G. Efficacy of spironolactone therapy in patients with true resistant hypertension. Hypertension. 55(1):147-152.

88. Umpierrez GE, Cantey P, Smiley D, et al. Primary aldosteronism in diabetic subjects with resistant hypertension. Diabetes Care. 2007;30(7):1699-1703.

89. Parving HH, Persson F, Lewis JB, Lewis EJ, Hollenberg NK. Aliskiren combined with losartan in type 2 diabetes and nephropathy. $N$ Engl J Med. 2008;358(23):2433-2446.

90. Patel A, MacMahon S, Chalmers J, et al. Effects of a fixed combination of perindopril and indapamide on macrovascular and microvascular outcomes in patients with type 2 diabetes mellitus (the ADVANCE trial) a randomised controlled trial. Lancet. 2007;370(9590):829-840.

91. Mogensen CE, Viberti G, Halimi S, et al. Effect of low-dose perindopril/indapamide on albuminuria in diabetes: preterax in albuminuria regression: PREMIER. Hypertension . 2003;41(5):1063-1071.

92. Bakris GL, Weir MR. Achieving goal blood pressure in patients with type 2 diabetes: conventional versus fixed-dose combination approaches. J Clin Hypertens (Greenwich). 2003;5(3):202-209.

93. Appel LJ, Brands MW, Daniels SR, Karanja N, Elmer PJ, Sacks FM. Dietary approaches to prevent and treat hypertension: a scientific statement from the American Heart Association. Hypertension. 2006;47(2):296-308.

94. Sacks FM, Svetkey LP, Vollmer WM, et al. Effects on blood pressure of reduced dietary sodium and the Dietary Approaches to Stop Hypertension (DASH) diet. DASH-Sodium Collaborative Research Group. N Engl J Med. 2001;344(1):3-10.

95. Neter JE, Stam BE, Kok FJ, Grobbee DE, Geleijnse JM. Influence of weight reduction on blood pressure: a meta-analysis of randomized controlled trials. Hypertension. 2003;42(5):878-884.

96. Stevens VJ, Obarzanek E, Cook NR, et al. Long-term weight loss and changes in blood pressure: results of the Trials of Hypertension Prevention, phase II. Ann Intern Med. 2001;134(1):1-11.

97. Whelton SP, Chin A, Xin X, He J. Effect of aerobic exercise on blood pressure: a meta-analysis of randomized, controlled trials. Ann Intern Med. 2002;136(7):493-503.

98. Smith SC Jr, Allen J, Blair SN, et al. AHA/ACC guidelines for secondary prevention for patients with coronary and other atherosclerotic vascular disease: 2006 update: endorsed by the National Heart, Lung, and Blood Institute. Circulation. 2006;113(19):2363-2372.

99. Rodbard HW, Jellinger PS, Davidson JA, et al. Statement by an American Association of Clinical Endocrinologists/American College of Endocrinology consensus panel on type 2 diabetes mellitus: an algorithm for glycemic control. Endocr Pract. 2009;15(6):540-559.

100. Gress TW, Nieto FJ, Shahar E, Wofford MR, Brancati FL. Hypertension and antihypertensive therapy as risk factors for type 2 diabetes mellitus. Atherosclerosis Risk in Communities Study. $N$ Engl J Med. 2000;342(13):905-912.

101. Gupta AK, Dahlof B, Dobson J, Sever PS, Wedel H, Poulter NR. Determinants of new-onset diabetes among 19,257 hypertensive patients randomized in the Anglo-Scandinavian Cardiac Outcomes Trial - Blood Pressure Lowering Arm and the relative influence of antihypertensive medication. Diabetes Care. 2008;31(5):982-988.

Integrated Blood Pressure Control

\section{Publish your work in this journal}

Integrated Blood Pressure Control is an international, peer-reviewed open-access journal focusing on the integrated approach to managing hypertension and risk reduction. Treating the patient and comorbidities together with diet and lifestyle modification and optimizing healthcare resources through a multidisciplinary team approach constitute key

\section{Dovepress}

features of the journal. This journal is indexed on American Chemical Society's Chemical Abstracts Service (CAS). The manuscript management system is completely online and includes a very quick and fair peerreview system, which is all easy to use. Visit http://www.dovepress.com/ testimonials.php to read real quotes from published authors. 